\title{
Epidemiologia das Leishmanioses no Estado de Goiás - 2002
}

\author{
Eduardo Rydan Manoel ${ }^{1}$ e Flávia Martins ${ }^{2}$
}

\section{INTRODUÇão}

As Leishmanioses ocorrem via de regra em áreas com precárias condições sócio econômicas, entretanto, existem poucos trabalhos avaliando o papel dos fatores que influenciam na distribuição da infecção e sua morbidade na população afetada. Em Goiás foi verificado nos últimos anos um aumento das áreas de transmissão e número de casos de Leishmaniose Tegumentar Americana (LTA) e Leishmaniose Visceral Americana (LVA), inclusive com transmissão urbana em alguns municípios.

Conhecer a distribuição das áreas de produção de novos casos, da fauna Flebotominea bem como implementar medidas de controle é de grande importância para o controle da endemia.

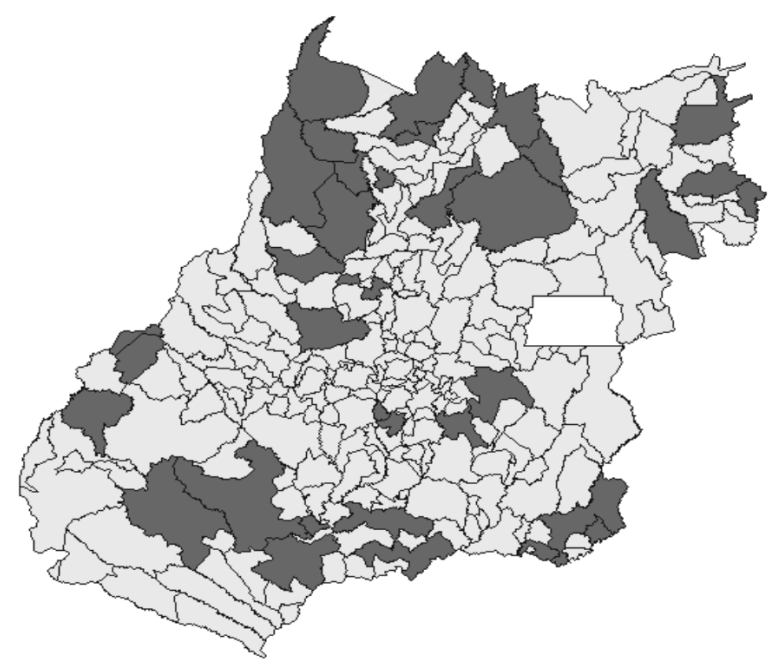

Fonte: MARTINS 2002

Figura 1 - Municípios com transmissão de LTA ou LVA em Goiás, entre as latitudes 13' 13'05", e 18 6'30" longitude $46^{\circ} 21 ' 22^{\prime \prime}$ e $50^{\circ} 53$ ' $"$ "'.

\section{OBJETIVO}

Com a análise dos dados coletados em 2002, mapeamento dos casos positivos, pretende-se avaliar epidemiologicamente as Leshmanioses e identificar as espécies de Flebotomíneos que ocorrem nos municípios com transmissão.

\section{MATERIAL E MÉTODOS}

Foi realizado levantamento dos dados epidemiológicos utilizando fichas de notificação dos casos confirmados de
ITA e LVA na Superintendência de Políticas de Atenção Integral à Saúde (SPAIS) e SINAN, avaliando esses casos por faixa etária, sexo, forma clínica e tipo de diagnóstico e alta. Foram mapeados os municípios com transmissão e realizadas capturas entomológicas em 38 deles para identificação das espécies do vetor que ocorrem nesses municípios. Foi realizado inquérito sorológico canino amostral em áreas com transmissão de LTA e em 100\% dos cães em áreas com transmissão de LVA.

\section{RESULTADOS}

Foram identificados em 2002, 109 municípios com transmissão de ITA, ou seja, quase metade dos 246 municípios que tem o Estado, com um total de 507 casos confirmados e 17 municípios com transmissão de LVA com 42 casos confirmados. Dos 507 casos de ITA, 24 (4,73\%) foi em menores de 10 anos e 483 (95,26\%) em maiores de 10 anos de idade (fig.2), 123 (36,09\%) do sexo feminino e 324 (63,90\%) do sexo masculino (Fig.3). A forma cutânea predominou com 397 casos (78,30\%) (Fig.4).

Quanto ao tipo de alta 260 (51,28\%) foi por cura (Fig.5) . 0 tipo de diagnóstico melhorou em relação a 2001, dos 507 casos de LTA, 445 (87,77\%) foram fechados através de diagnóstico laboratorial, apenas $62(12,23 \%)$ pela clínica (Fig.6).

\section{Faixa etária}

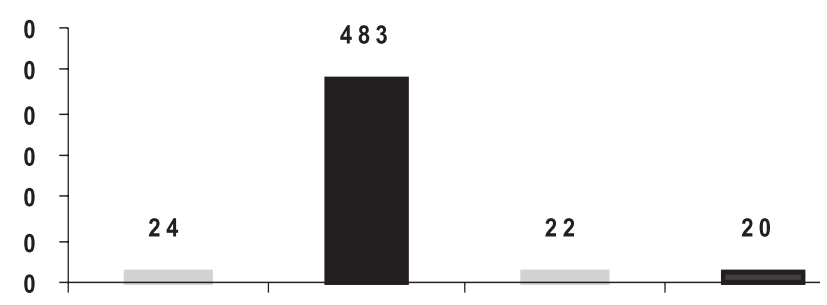

Fonte: SINAN

Figura 2 - Distribuição de casos por faixa etária.

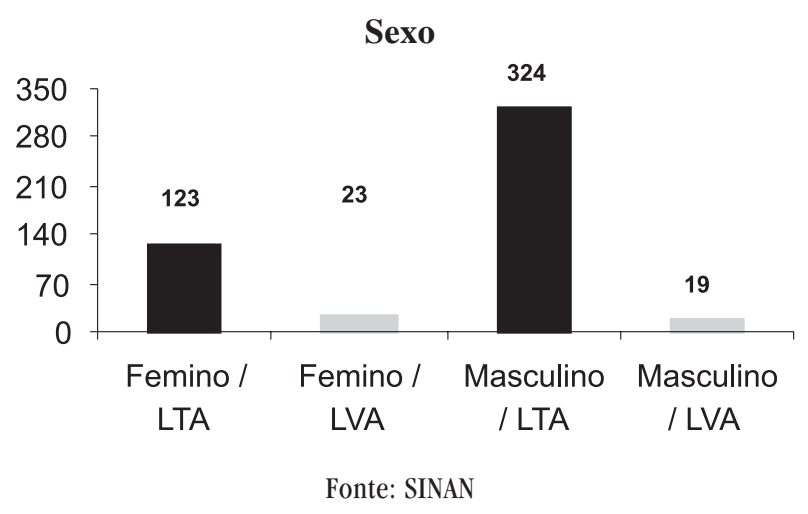

Figura 3 - Distribuição de casos por sexo.

${ }^{1}$ Superintendência de Políticas de Atenção Integral à Saúde (SPAIS) - ${ }^{2}$ Laboratório Central-Go (LACEN) 


\section{Forma Clínica}

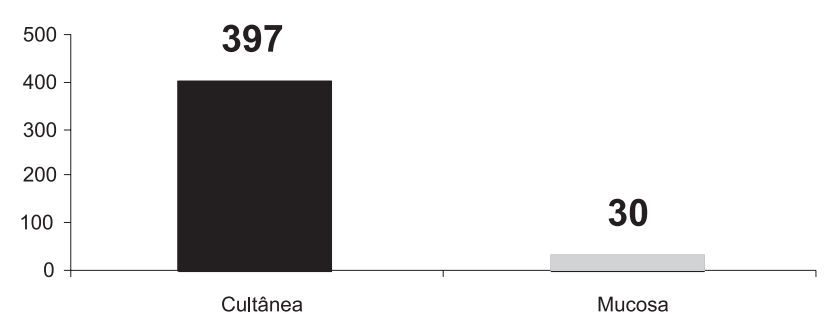

Fonte: SINAN

Figura 4 - Número de casos conforme forma clínica.

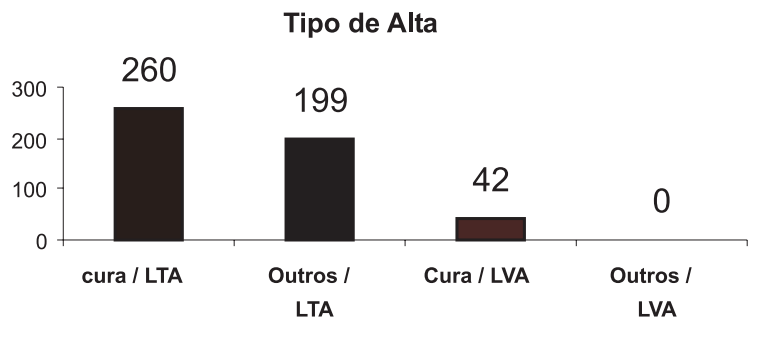

Fonte: SINAN

Figura 5 - Distribuição dos casos por tipo de alta.

Dos 42 casos confirmados de LVA, 22 (52\%) são em menores de 10 anos e 20 (48\%) em maiores de 10 anos de idade, 23 casos (53\%) do sexo feminino e 19 (47\%) do sexo masculino. Quanto ao tipo de alta 42 casos (100\%) foi por cura. Foram capturados 2061 flebotomíneos e identificadas 19 espécies com maior frequiência: Lutzomyia longipalpis com 38,54\%,
Tipo de Diagnóstico - LTA

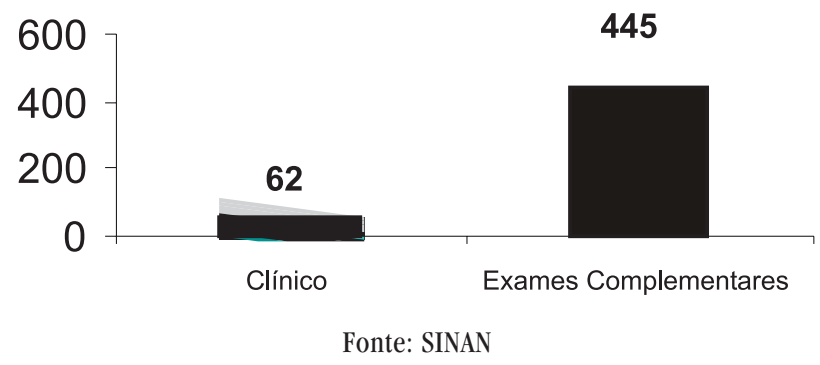

Figura 6 - Distribuição de casos por diagnóstico

L.whitimani com $21,83 \%$, L. intermédia com $19,82 \%$, L. lenti entre ouras com menores frequiências.

Após as capturas entomológicas, foi realizada uma aplicação de cipermetrina 40\% PM com bomba costal motorizada nos imóveis e anexos. Potenciais criadouros como chiqueiros e galinheiros foram afastados dos imóveis ou retirados da zona urbana dos municípios. São realizadas capturas entomológicas bimestrais nas áreas, para avaliação de frequiência e sazonalidade da fauna Flebotominea.

\section{BIBLIOGRAFIA}

1. Camargo-Neves V.L.F., Gomes A.C, Antunes J.L.F. 2002. Correlação da presença de espécies de flebotomineos (Díptera, Psychodidae) com registros de casos de LTA no Estado de São Paulo, Brasil. Rev Soc Med Trop, 35:299-306.

2. Martins, F. 2002. Diversidade e frequiência na fauna flebotominea em áreas com transmissão de Leihmaniose, no Estado de Goiás. Rev. Pat. Trop.,31(2): 311-224, jul/dez 